\title{
Making a Difference Through Improving Teamwork in the Operating Room: A Systematic Review of the Evidence on What Works
}

\author{
Jennifer Weller • Matthew Boyd
}

Published online: 4 February 2014

(C) Springer Science + Business Media New York 2014

\begin{abstract}
Surgical patients are at risk of harm from avoidable adverse events, many of which are at least in part attributable to failures in teamwork and communication. We undertook a systematic review of studies of interventions to improve teamwork and communication in the operating room (OR) that measured an outcome important for patient care in the clinical environment. We found good evidence to support several interventions: structured approaches to information sharing between OR team members; ongoing programmes of team training; and organisational changes to support team function. Many studies demonstrated improved team function in the clinical environment, improved OR processes, and/or improved patient outcomes. This review identified successful approaches to improving teamwork and communication in the OR and provided recommendations for practice.
\end{abstract}

Keywords Multidisciplinary · Interprofessional ·

Teamwork · Operating room - Anaesthesiology ·

Communication

\section{Introduction}

Every year millions of people are disabled or die because of adverse events in hospital. A recent study puts the number of adverse events at approximately $10 \%$ of hospitalisations globally, or 42.7 million incidents annually. For patients, this equates to 23 million years lost through

J. Weller $(\bowtie) \cdot$ M. Boyd

Centre for Medical and Health Sciences Education,

School of Medicine, University of Auckland, Private Bag 92019,

Auckland 1142, New Zealand

e-mail: j.weller@auckland.ac.nz disability or death every year [1]. Reducing potentially avoidable harm in hospitalised patients must be a key focus for advancing the quality of medical care for this century.

There is abundant evidence that failures in teamwork and communication contribute to these millions of adverse events. The operating room (OR) is a high-acuity, complex, and error-prone environment that is vulnerable to adverse events, and we now have considerable evidence that failures in teamwork and communication in the OR are frequent and affect patient care: an analysis of recordings of six complex operations found one communication failure every $8 \mathrm{~min}$ [2], and an observational study found communication failures in approximately $30 \%$ of team exchanges, with a third of these resulting in effects that could threaten patient safety [3]. Communication between surgeons and anaesthesiologists has been evaluated as poor in a number of studies [4-6].

Professional 'tribalism' may account for some of these communication and teamwork difficulties [7]. OR team members often have limited understanding of the roles and capabilities of those from different disciplines [8, 9], which may cause conflict and hinder the achievement of team goals. Furthermore, OR staff may not always have insight into their lack of awareness: an interview-based study found that OR professionals tended to overrate their own understanding of their colleagues' roles relative to the understanding that colleagues attributed to them, and this was especially a tendency among surgeons [5].

Operating room team members may have limited insight into their own impact on team dynamics. In one study, surgeons, nurses and anaesthesiologists independently rated three video-based scenarios for the three professions' level of tension, responsibility for creating tension, and responsibility for resolution. The three professions rated tension levels of the various scenarios similarly, but often 
Table 1 Model for effective teams

\begin{tabular}{|c|c|}
\hline \multicolumn{2}{|c|}{ Underpinning mechanisms for effective teamwork } \\
\hline $\begin{array}{l}\text { Shared mental } \\
\text { models }\end{array}$ & $\begin{array}{l}\text { A common understanding among the team of } \\
\text { the tasks, goals, and capabilities of the team, } \\
\text { which allows for coordinated organisation of } \\
\text { activities }\end{array}$ \\
\hline Mutual trust & $\begin{array}{l}\text { The shared belief that team members will } \\
\text { perform their roles and protect the interests of } \\
\text { their teammates }\end{array}$ \\
\hline $\begin{array}{l}\text { Closed-loop } \\
\text { communication }\end{array}$ & $\begin{array}{l}\text { The exchange of information that is directed } \\
\text { from a sender to a receiver and confirmed or } \\
\text { read-back by the receiver }\end{array}$ \\
\hline \multicolumn{2}{|c|}{ Dimensions of effective teamwork } \\
\hline Team leadership & $\begin{array}{l}\text { Ability to direct and coordinate the activities of } \\
\text { the other team members, assess team } \\
\text { performance, assign tasks, develop team } \\
\text { knowledge, skills, and abilities, motivate team } \\
\text { members, plan and organise, and establish a } \\
\text { positive atmosphere }\end{array}$ \\
\hline $\begin{array}{l}\text { Mutual } \\
\text { performance } \\
\text { monitoring }\end{array}$ & $\begin{array}{l}\text { Ability to develop common understanding of the } \\
\text { team environment and apply appropriate } \\
\text { strategies to accurately monitor teammate } \\
\text { performance }\end{array}$ \\
\hline $\begin{array}{l}\text { Backup } \\
\text { behaviour }\end{array}$ & $\begin{array}{l}\text { Ability to anticipate other team members' needs } \\
\text { through accurate knowledge about their } \\
\text { responsibilities. This includes the ability to } \\
\text { shift workload among members to achieve } \\
\text { balance during periods of high workload or } \\
\text { pressure }\end{array}$ \\
\hline Adaptability & $\begin{array}{l}\text { Ability to adjust strategies based on information } \\
\text { gathered from the environment including how } \\
\text { the team is managing the situation. Altering } \\
\text { course of action or team member task } \\
\text { allocation in response to changing conditions } \\
\text { [internal or external] }\end{array}$ \\
\hline Team orientation & $\begin{array}{l}\text { Propensity to take other's behaviour into } \\
\text { account during group interactions and the } \\
\text { belief in the importance of the team's goal } \\
\text { over the individual members' goal }\end{array}$ \\
\hline
\end{tabular}

Data from Salas et al. [11•]

rated their own profession as having relatively less responsibility than the others for creating and resolving tension [10].

There is good evidence about the components of effective teamwork. Salas et al. [11•] proposed a useful model incorporating five key dimensions of effective teams with three underpinning mechanisms. The key dimensions are leadership, team orientation, mutual performance monitoring, backup behaviour, and adaptability. Underpinning these are: a shared mental model, mutual trust, and closed loop communication (Table 1).

We have identified that adverse events are common and contribute significantly to poor outcomes for patients; we have identified that teamwork and communication are key contributors to these adverse events; we have a theoretical model of what effective teams look like.
We were interested in finding out, from the perspective of anaesthesiologists, what interventions to improve teamwork and communication in the OR had evidence supporting their effectiveness.

To this end, we undertook a systematic review of studies that evaluated interventions to improve teamwork and communication in the OR that had measured the impact of the intervention on the way teams functioned in the $\mathrm{OR}$, on processes in the OR, or on patient outcomes. Our focus was on studies that demonstrated an effect in the clinical environment.

\section{Method: Looking for Evidence}

We conducted a search of the MEDLINE [Ovid] database on 15 August 2013 using the search strategy: [(team\$ or interprofessional or multidisciplinary or interdisciplinary) and ("operating room" or theatre or "surgical suite")]. We limited the findings to articles published since 2003. This resulted in identifying 1,242 articles. From these we excluded case reports, articles that were not in English, not set in the OR, or reported only on technical procedures. Articles were included if the title mentioned "safety" or "errors" or "briefing" or "checklists" or "communication" or "team training" or another team process. After this, 287 articles remained, 13 of which were duplicates.

These 287 articles were obtained and reviewed. We excluded the following:

(1) Articles that did not include the anaesthesia team, included only one OR subteam, or were not set in the OR (i.e. we excluded PACU, ward, nursing team only, surgical team only).

(2) Letters, opinion pieces, or commentary on primary studies.

(3) Articles that reported measurement tools only.

(4) Articles that assessed only knowledge, not attitudes or behaviour (measurements of changes in attitudes were included but post-test knowledge reports were not).

(5) Articles that did not evaluate an intervention in comparative fashion (i.e. we excluded post-intervention descriptive studies if there were no control or pre-intervention data).

(6) Articles that did not report data from the clinical setting (i.e. post-course, end-of-day evaluations were excluded).

(7) Studies that did not report a teamwork process (or attitude), OR process, or patient outcome.

We included seven additional articles we were aware of from other sources. A check of the reference lists of all included articles plus 13 review articles discovered in the course of the search identified a further nine articles. In total we included 46 articles in the review. 
Each article was then reviewed and the following recorded: author, year, intervention category (checklist, briefing, team training, other), site, design, OR specialty, study population, number of participants, the intervention, the comparison group, length of follow-up, teamwork process measured, medical management process measured, and patient outcome.

\section{Results: What Works}

Studies of interventions to improve teamwork fell into four main categories: briefing protocols (6 studies), checklists (17 studies), inter-professional team training (20 studies), and organisational change ( 3 studies).

\section{Briefing Protocols}

Briefing of the OR team prior to beginning a case enables the development of a shared team mental model about the goals for surgery and any potential difficulties, and it allows the different team members to contribute to decision-making and plan ahead. There is good evidence that preoperative briefings improve communication between team members and save the lives of patients.

A preoperative briefing checklist or protocol can improve team attitudes towards safety [12] and decrease delays and breakdowns in communication between team members $[13,14]$ with significant reductions in observed failures in communication $[15,16 \bullet]$. Furthermore, briefings can reduce the rate of non-routine surgical events [17] and disruptions to surgery [15], and there is a suggestion that the incidence of wrong-site surgery is decreased [12].

Factors contributing to the success of programmes to introduce briefing into the OR include engagement of OR leaders and managers, an extended period of implementation, engaging OR team members in the development of the items to be included in the briefing, video modelling of ideal implementation, and in-theatre prompting and feedback on the use of the briefing during the introductory phase $[16 \bullet, 18,19]$.

The Veterans' Health Administration (VHA) instituted a comprehensive programme of team training that includes a briefing component. Evaluation of this intervention suggests that compliance with the briefing is directly related to patient mortality. Where the degree to which a facility had embraced briefings was rated on a four-point scale, they found 6 lives per 10,000 could be saved for every point improvement on the scale. If OR teams changed their practices from no or limited briefing and adopted a highquality preoperative briefing, this could save two lives for every 1,000 operative patients $[20 \bullet \bullet$.

\section{Checklists}

Checklists can structure information sharing and, like briefings, aid the development of shared team mental models, identify errors and omissions, and improve communication between health professionals. The WHO Surgical Safety Checklist (WHO SSC) [21•] was designed for use within the OR. One aim, amongst others, was to improve teamwork. The Checklist includes items requiring introduction of team members and their roles, and invites expressions of concern. The Surgical Patient Safety System (SURPASS) checklist [22•*] extends beyond the OR to include the entire surgical patient journey. Substantial benefits for patients from both checklists have been reported.

The WHO SSC [21 , 23-32] has been evaluated in longitudinal studies comparing pre- and post-implementation, and in between-hospital comparisons. Significant reductions in deaths and complication rates have been reported. A controlled trial of the SURPASS checklist at six intervention and five control hospitals in The Netherlands found complication rates decreased from 27.3 per 100 patients to 16.7 (a $38.9 \%$ reduction) in the intervention hospitals and mortality also significantly declined $(1.5-0.8 \%)$. There was no change in the control hospitals [22••]. Better checklist compliance was associated with lower rates of complications [22••]. This result is supported by studies on the WHO SSC $[21 \cdot, 27,30-32]$ where the aggregate mortality rate (pre-intervention 19,417 patients, post-intervention 16,499 patients) decreased from 2.81 to $2.24 \%$. Decreases in complications after WHO SSC introduction ranged from 10.6 to $59.0 \%$ [21•, 27, 30, 32].

The use of checklists has been associated with an increase in compliance with various important actions: antibiotic timing [18, 27] and DVT prophylaxis [18, 33]; patient identity checks [34]; and frequency of sign-in, timeout, and sign-out $[23,35]$. Checklists appear to improve communication between the anaesthesiologist and surgeon preoperatively [34] and improve the self-reported safety climate or teamwork attitudes [24-26].

The specific components of these checklists necessary to achieve their potential benefits are unclear. It may be that staff become more attuned to a culture of safety when checklists are employed, or that sharing of names and roles facilitates the development of the team. However, despite the compelling evidence on the effectiveness of checklists, compliance with checklist completion is often low [31].

\section{Team Training}

Interprofessional team training interventions have been shown to have significant positive effects on OR processes, teamwork attitudes, and team processes, with some 
evidence of improved patient outcomes. Improved OR processes include reduced incorrect surgical counts [36]; more timely antibiotic administration, DVT prophylaxis, and beta-blockade [37, 38]; and reduced technical and procedural errors, and increased compliance with briefings, checklists, and time-out [38-41]. Team training has also been shown to reduce OR room turnover time [37], increase the percentage of cases starting on time, and reduce case delays $[37,39,42]$.

Teamwork training can also improve teamwork processes in the OR and staff attitudes towards safety [36, 39, 42-45]. Reduced communication errors [39] and improved scores for communication between team members [38] have been reported. Scores for teamwork in OR teams have also been shown to improve in some studies. McCulloch et al. [43] found significant improvements in scores on a validated teamwork in the OR rating tool (NOTECHS) using a pre-/post-intervention study design, although this hasn't been convincingly replicated in other studies [40]. One of the difficulties with such studies is the reliability of the measurement tools, and the variable clinical challenges, team composition, and surgical context in the OR.

There is some evidence supporting reduced patient mortality and morbidity following team training interventions [20••, 37, 39, 43, 46, 47]. One study demonstrated reduction in the rate of retained foreign bodies [46]. However, other studies have reported no change to morbidity and mortality statistics [39], and some of the positive findings have been in multimodal interventions, which included a range of interventions including the introduction of briefing and debriefing checklists [20••].

Some common features are apparent in effective team training interventions. The VHA team training programme [20•*] and the Team STEPPS programme [48] are both very comprehensive, targeting all of the elements in Salas' model of teamwork. The training is led by senior clinical staff and is conducted with all multidisciplinary members of the OR team together. The educational methods involve active participation in role plays and video modelling of good teamwork. The VHA intervention is sustained with quarterly follow-up calls to each site and is mandated topdown, but with local site flexibility.

Finally, team training using simulation has shown improvement, 1 year after an interactive workshop, in the perception that all OR personnel are working as a team in cardiac surgery [49]. No other simulation studies in our search reported an impact in the clinical OR post-training.

\section{Organisational Change}

Observation and analysis of how OR teams function can also suggest strategies for improvement. We found three studies that described an organisational change: one study of a process redesign, one introducing structured communication protocols, and one evaluating an intervention on team composition.

One study prospectively observed the workflow of OR team members and changes were implemented where inefficiencies were observed. Workflow diagrams were used to highlight inefficiencies and identify critical moments of overload where brief backup from other personnel was needed. The redesign resulted in decreased OR turnaround time [50].

In cardiac surgery, the aviation industry's 'sterile cockpit', where communications are protocol-based during take-off and landing, provided the basis for a structured communication protocol for eight critical events in cardiopulmonary bypass. Importantly 'call-back' of all exchanges was instituted as a standard procedure. These structured communication protocols, including closed-loop communication, reduced communication breakdowns significantly [51].

Having a fixed team throughout the day, rather than having team members come and go, seems to improve teamwork. In two hospitals performing bariatric surgery, roster changes were made to keep team composition stable throughout the day. This intervention improved the perceptions of teamwork and safety climate and decreased operative time [52].

\section{Discussion}

It is clear that many of the above interventions have the potential to improve patient safety. Briefings, use of checklists such as the WHO SSC and SURPASS, team training and well-informed organisational changes can improve OR processes and team function, and reduce harm to patients. Successful interventions often target one or more aspects of the theoretical model for effective teams [11•] (Table 1). Different interventions can each target different aspects of teamwork, so a multimodal approach would seem most likely to be effective.

A shared team mental model, i.e. a shared understanding of the plan and goals and each person's responsibilities, is crucial for good team function and is supported by preoperative briefings and checklists. Mutual performance monitoring is supported by checklists, ensuring that all members are aware the others have completed their tasks. This invites backup behaviour and builds mutual trust. Closed-loop communication is directly targeted in several interventions, most notably the introduction of communication protocols in cardiac surgery [51]. Outside of the OR, similar findings are being reported with unanticipated improvements in patient morbidity and mortality from interventions where the whole multidisciplinary patient 
care team meets every day to discuss and agree on the concerns and plan for care for the patient [53].

The effects of some of these interventions appear to decay. Forse et al. [37] observed over 4 years, where processes at first improved then started to revert. Halverson et al. [39] noted decreases in briefing compliance over time. Nurok et al. [54] found that the effect was not sustained, although some studies report that effects increase with time as the interventions become institutionalised [20•]. This suggests a need for on-going monitoring and evaluation.

Given the disparate nature of the studies included, we did not undertake a quantitative meta-analysis. Some studies measuring similar outcome variables used different measurement tools, such as the American College of Surgeons National Surgical Quality Improvement Programme list of postoperative complications in several studies of the WHO checklist, whereas the Dutch National Surgical Adverse Event Registration System was used to evaluate the SURPASS Checklist.

Many researchers have described interventions to improve teamwork and communication. Of note, simulation-based team training is well established in anaesthesia. It was therefore somewhat surprising that only one simulation-based study met our criteria for inclusion. This is likely to reflect the difficulty of collecting the evidence in the clinical environment rather than the value of such interventions. While there is evidence that behaviours in the simulated environment do reflect those in the clinical environment [55, 56], the focus of this review was restricted to measurable changes to processes or team function in the clinical environment or to patient outcome.

Simulation-based studies have added observational evidence on communication failures and errors to guide interventions [57, 58], have successfully taught strategies to improve communication and teamwork [59], have demonstrated improved teamwork and information sharing in the simulation environment [60-62], and have facilitated the development and validation of instruments to measure teamwork in the clinical environment [63, 64]. Also, a recent simulation study suggested that crisis checklists increase adherence to lifesaving processes of care [65].

Simulation can provide a powerful trigger to challenge assumptions, identify deficiencies in communication, and change attitudes. Simulation could potentially lay the groundwork for a more team-oriented approach to clinical practice and facilitate the introduction of processes such as checklists and briefings.

\section{Limitations}

The nature of much teamwork research in the OR means that studies are predominantly pre- and post-intervention studies, frequently with data collected by self-report. Such studies are at risk of bias from confounding factors, a lack of blinding, and influences such as the Hawthorne effect. Many of the studies we report possess an inherent risk of bias that could affect the interpretation of results. Nevertheless, we believe there are several key well-constructed studies reported here, which offer relatively unambiguous evidence for the benefits of teamwork interventions. These interventions include checklists, briefings, and sophisticated team training programmes.

\section{Conclusion}

No amount of protocols or skills training will work, or have a sustained effect, if the culture of the OR is such that team members-or even one team member-fail to engage. It seems likely that a multimodal and multidisciplinary approach is needed to both develop the skills and organisational structure required to support teamwork and, importantly, to develop a culture committed to reducing patient harm by embracing a team-based approach to care of surgical patients. Anaesthesiologists have led the way in interventions to improve patient safety and are well placed to provide leadership in the OR to implement evidenced-based strategies to improve teamwork and communication.

\section{Compliance with Ethics Guidelines}

Conflict of Interest Jennifer Weller and Matthew Boyd declare that they have no conflict of interest.

Human and Animal Rights and Informed Consent This article does not contain any studies with human or animal subjects performed by any of the authors.

\section{References}

Papers of particular interest, published recently, have been highlighted as:

- Of importance

•• Of major importance

1. Jha AK, Larizgoitia I, Audera-Lopez C, Prasopa-Plaizier N, Waters H, Bates DW. The global burden of unsafe medical care: analytic modelling of observational studies. BMJ Qual Saf. 2013;22:809-15.

2. Hu Y-Y, Arriaga AF, Peyre SE, Corso KA, Roth EM, Greenberg CC. Deconstructing intraoperative communication failures. J Surg Res. 2012;177:37-42.

3. Lingard L, Espin S, Whyte S, Regehr G, Baker GR, Reznick R, et al. Communication failures in the operating room: an observational classification of recurrent types and effects. Qual Saf Health Care. 2004;13:330-4. 
4. Sevdalis N, Wong HWL, Arora S, Nagpal K, Healey A, Hanna GB, et al. Quantitative analysis of intraoperative communication in open and laparoscopic surgery. Surg Endosc. 2012;26:2931-8.

5. Undre S, Sevdalis N, Healey AN, Darzi SA, Vincent CA. Teamwork in the operating theatre: cohesion or confusion? J Eval Clin Pract. 2006;12:182-9.

6. Elks KN, Riley RH. A survey of anaesthetists' perspectives of communication in the operating suite. Anaesth Intensive Care. 2009;37:108-11.

7. Buljac-Samardzic M, Dekker-van-Dorn C, van Wijngaarden J, van Wijk K. Interventions to improve team effectiveness: a systematic review. Health Policy. 2010;94:183-95.

8. Coe R, Gould D. Disagreement and aggression in the operating theatre. J Adv Nurs. 2008;61:609-18.

9. Weller JM, Janssen AL, Merry AF, Robinson B. Interdisciplinary team interactions: a qualitative study of perceptions of team function in simulated anaesthesia crises. Med Educ. 2008;42:382-8.

10. Lingard L, Regehr G, Espin S, Devito I, Whyte S, Buller D, et al. Perceptions of operating room tension across professions: building generalizable evidence and educational resources. Acad Med. 2005;80(10 Suppl):S75-9.

11. - Salas E, Sims D, Burke C. Is there a "Big Five" in Teamwork? Small Group Res. 2005;36:555-599. Eduardo Salas is a world expert on effective teamwork across a number of industries. His model of the components of effective teamwork serves as a useful framework within which to target and evaluate team training interventions in healthcare.

12. DeFontes J, Surbida S. Preoperative safety briefing project. Permanente J. 2004;8:21-7.

13. Nundy S, Mukherjee A, Sexton JB, Pronovost PJ, Knight A, Rowen LC, et al. Impact of preoperative briefings on operating room delays: a preliminary report. Arch Surg. 2008;143:1068-72.

14. Paige JT, Aaron DL, Yang T, Howell DS, Chauvin SW. Improved operating room teamwork via SAFETY prep: a rural community hospital's experience. World J Surg. 2009;33:1181-7.

15. Henrickson SE, Wadhera RK, Elbardissi AW, Wiegmann DA, Sundt TM 3rd. Development and pilot evaluation of a preoperative briefing protocol for cardiovascular surgery. J Am Coll Surg. 2009;208:1115-23.

16. • Lingard L, Regehr G, Orser B, Reznick R, Baker GR, Doran D, et al. Evaluation of a preoperative checklist and team briefing among surgeons, nurses, and anesthesiologists to reduce failures in communication. Arch Surg. 2008;143:12-17. Given that root cause analysis links communication errors to adverse events, this study demonstrates a possible mechanism through which team briefings may lower adverse events. It demonstrates a significant reduction in communication failures after the introduction of case briefings.

17. Einav Y, Gopher D, Kara I, Ben-Yosef O, Lawn M, Laufer N, et al. Preoperative briefing in the operating room: shared cognition, teamwork, and patient safety. Chest. 2010;137:443-9.

18. Paull DE, Mazzia LM, Wood SD, Theis MS, Robinson LD, Carney B, et al. Briefing guide study: preoperative briefing and postoperative debriefing checklists in the Veterans Health Administration medical team training program. Am J Surg. 2010;200:620-3.

19. Paull DE, Mazzia LM, Izu B, Neily J, Mills PD, Bagian JP. Predictors of successful implementation of preoperative briefings and postoperative debriefings after medical team training. Am J Surg. 2009;198:675-8.

20. •• Neily J, Mills PD, Young-Xu Y, Carney BT, West P, Berger DH, et al. Association between implementation of a medical team training program and surgical mortality. JAMA. 2010;304:1693-1700. This large study of 108 Veterans Health Administration Hospitals provides a controlled demonstration of the association between a mandated team training programme and decreased surgical mortality. The sheer size of this study makes its conclusions about the generalisability of team training effectiveness hard to ignore.

21. Haynes AB, Weiser TG, Berry WR, Lipsitz S, Breizat A-HS, Dellinger EP, et al. A surgical safety checklist to reduce morbidity and mortality in a global population. NEJM. 2009;360:491-499. This is the first study to demonstrate the association between the WHO Surgical Safety Checklist and reduced surgical mortality. It does so across eight locations globally.

22. • de Vries EN, Prins HA, Crolla RMPH, den Outer AJ, van Andel G, van Helden SH, et al. Effect of a comprehensive surgical safety system on patient outcomes. NEJM. 2010;363:1928-1937. This study demonstrates the effectiveness of a comprehensive surgical safety checklist in reducing surgical complications. This is a significant study that addresses some shortcomings of the WHO Surgical Safety Checklist study (Haynes 2009) by including control hospitals where no reduction in complications was demonstrated. The fact this study took place in The Netherlands diminishes the weight of criticisms claiming that checklists only have their effect in hospitals where standard of care is poor.

23. Abdel-Rehim S, Morritt A, Perks G. WHO surgical checklist and its practical application in plastic surgery. Plast Surg Int 2011. 2011;2011:579579.

24. Bohmer AB, Wappler F, Tinschmann T, Kindermann P, Rixen D, Bellendir $\mathrm{M}$, et al. The implementation of a perioperative checklist increases patients' perioperative safety and staff satisfaction. Acta Anaesth Scand. 2012;56:332-8.

25. Haynes AB, Weiser TG, Berry WR, Lipsitz SR, Breizat A-HS, Dellinger EP, et al. Changes in safety attitude and relationship to decreased postoperative morbidity and mortality following implementation of a checklist-based surgical safety intervention. BMJ Qual Saf. 2011;20:102-7.

26. Helmio P, Blomgren K, Takala A, Pauniaho SL, Takala RSK, Ikonen TS. Towards better patient safety: WHO surgical safety checklist in otorhinolaryngology. Clin Otolaryngol. 2011;36:242-7.

27. Kwok AC, Funk LM, Baltaga R, Lipsitz SR, Merry AF, Dziekan $\mathrm{G}$, et al. Implementation of the World Health Organization surgical safety checklist, including introduction of pulse oximetry, in a resource-limited setting. Ann Surg. 2013;257:633-9.

28. Norton E, Rangel S. Implementing a pediatric surgical safety checklist in the OR and beyond. AORN J. 2010;91:61-71.

29. Oszvald A, Vatter H, Byhahn C, Seifert V, Guresir E. "Team time-out" and surgical safety-experiences in 12,390 neurosurgical patients. Neurosurg Focus. 2012;33(5):E6.

30. Sewell M, Adebibe M, Jayakumar P, Jowett C, Kong K, Vemulapalli K, et al. Use of the WHO surgical safety checklist in trauma and orthopaedic patients. Int Orthop. 2011;35:897-901.

31. van Klei W, Hoff R, van Aarnhem E, Simmermacher R, Regli L, Kappen T, et al. Effects of the Introduction of the WHO "Surgical Safety Checklist" on In-Hopsital Mortality. Ann Surg. 2011;255:44-9.

32. Weiser TG, Haynes AB, Dziekan G, Berry WR, Lipsitz S, Gawande AA. Effect of a 19-item surgical safety checklist during urgent operations in a global patient population. Ann Surg. 2010;251:976-80.

33. Lee BT, Tobias AM, Yueh JH, Bar-Meir ED, Darrah LM, Guglielmi CL, et al. Design and impact of an intraoperative pathway: a new operating room model for team-based practice. J Am Coll Surg. 2008;207:865-73.

34. Takala RSK, Pauniaho SL, Kotkansalo A, Helmio P, Blomgren $\mathrm{K}$, Helminen M, et al. A pilot study of the implementation of WHO surgical checklist in Finland: improvements in activities and communication. Acta Anaesth Scand. 2011;55:1206-14. 
35. Mainthia R, Lockney T, Zotov A, France DJ, Bennett M, St Jacques PJ, et al. Novel use of electronic whiteboard in the operating room increases surgical team compliance with preincision safety practices. Surgery. 2012;151:660-6.

36. Rivers R, Swain D, Nixon W. Using aviation safety measures to enhance patient outcomes. AORN J. 2003;77:158-62.

37. Forse R, Bramble JD, McQuillan R. Team training can improve operating room performance. Surgery. 2011;150:771-8.

38. Awad SS, Fagan SP, Bellows C, Albo D, Green-Rashad B, De la Garza M, et al. Bridging the communication gap in the operating room with medical team training. Am J Surg. 2005;190:770-4.

39. Halverson AL, Andersson JL, Anderson K, Lombardo J, Park CS, Rademaker AW, et al. Surgical team training: the Northwestern Memorial Hospital experience. Arch Surg. 2009;144:107-12.

40. Catchpole K, Dale T, Hirst G, Smith J, Giddings T. A multicentre trial of aviation-style training for surgical teams. J Patient Saf. 2010;6:180-6.

41. Sax HC, Browne P, Mayewski R, Panzer R, Hittner K, Burke R, et al. Can aviation-based team training elicit sustainable behavioural change. Arch Surg. 2009;144:1133-7.

42. Wolf FA, Way LW, Stewart L. The efficacy of medical team training: improved team performance and decreased operating room delays: a detailed analysis of 4,863 cases. Ann Surg. 2010;252:477-83.

43. McCulloch P, Mishra A, Handa A, Dale T, Hirst G, Catchpole K. The effects of aviation-style non-technical skills training on technical performance and outcome in the operating theatre. Qual Saf Health Care. 2009;18:109-15.

44. Carney BT, West P, Neily J, Mills PD, Bagian JP. Changing perceptions of safety climate in the operating room with the Veterans Health Administration medical team training program. Am J Med Qual. 2011;26:181-4.

45. Bleakley A, Allard J, Hobbs A. Towards culture change in the operating theatre: embedding a complex educational intervention to improve teamwork climate. Med Teach. 2012;34:e635-40.

46. Cima RR, Kollengode A, Storsveen A, Weisbrod C, Deschamps C, Koch M, et al. A multidisciplinary team approach to retained foreign objects. Jt Comm J Qual Patient Saf. 2009;35:123-32.

47. Young-Xu Y, Neily J, Mills PD, Carney BT, West P, Berger DH, et al. Association between implementation of a medical team training program and surgical morbidity. Arch Surg. 2011;146:1368-73.

48. Weaver SJ, Rosen MA, DiazGranados D, Lazzara EH, Lyons R, Salas E, et al. Does teamwork improve performance in the operating room? A multilevel evaluation. Jt Comm J Qual Patient Saf. 2010;36:133-42.

49. Stevens L, Cooper JB, Raemer D, Schneider R, Frankel A, Berry WR, et al. Educational program in crisis management for cardiac surgery teams including high realism simulation. Cardiothorac Surg Educ Train. 2012;144:17-24.

50. Cendan J, Good M. Interdisciplinary work flow assessment and redesign decreases operating room turnover time and allows for additional caseload. Arch Surg. 2006;141:65-9.

51. Wadhera RK, Parker SH, Burkhart HM, Greason KL, Neal JR, Levenick KM, et al. Is the "sterile cockpit" concept applicable to cardiovascular surgery critical intervals or critical events? The impact of protocol-driven communication during cardiopulmonary bypass. J Thoracic Cardiovasc Surg. 2010;139:312-9.
52. Stepaniak PS, Heij C, Buise MP, Mannaerts GHH, Smulders JF, Nienhuijs SW. Bariatric surgery with operating room teams that stayed fixed during the day: a multicenter study analyzing the effects on patient outcomes, teamwork and safety climate, and procedure duration. Anesth Analg. 2012;115:1384-92.

53. Stein J, Mohan A, Payne C, Castle B, Burleson M, Methvin A, et al. Mortality reduction associated with structure, process, and management redesign of a hospital medicine unit. Society of Hospital Medicine Abstract Issue; April 1-4; San Diego 2012.

54. Nurok M, Lipsitz S, Satwicz P, Kelly A, Frankel A. A novel method for reproducibly measuring the effects of interventions to improve emotional climate, indices of team skills and communication, and threat to patient outcome in a high-volume thoracic surgery center. Arch Surg. 2010;145:489-95.

55. Weller J, Torrie J, Shulruf B, Henderson R, Merry A, Henderson $\mathrm{K}$, et al. The validity of simulation for team training for patient safety in anaesthesia: an observational study comparing team interactions in the operating room and the simulated environment. In: WFSA, editor. 15th WFSA World Congress of Anaesthesiologists; Buenos Aires2012.

56. Manser T, Dieckmann P, Wehner T, Rallf M. Comparison of anaesthetists' activity patterns in the operating room and during simulation. Ergonomics. 2007;50:246-60.

57. Manser T, Harrison TK, Gaba DM, Howard SK. Coordination patterns related to high clinical performance in a simulated anesthetic crisis. Anesth Analg. 2009;108:1606-15.

58. Bogenstatter Y, Tschan F, Semmer N, Spychiger M, Breuer M, Marsch S. How accurate is information transmitted to medical professionals joining a medical emergency? A simulator study. Hum Factors. 2009;51:115-25.

59. Weller J, Torrie J, Boyd M, Frengley R, Garden S, Ng WL, et al. Improving team information sharing with a structured call-out in anaesthetic emergencies: a randomised controlled trial. Brit $\mathbf{J}$ Anaesth. 2014 (in press).

60. Frengley RW, Weller J, Torrie J, Dzendrowskyj P, Yee B, Paul $\mathrm{AM}$, et al. The effect of a simulation-based training intervention on the performance of established critical care unit teams. Crit Care Med. 2011;39:2605-11.

61. Cumin D, Boyd MJ, Webster CS, Weller JM. A systematic review of simulation for multidisciplinary team training in operating rooms. Simul Healthc. 2013;8:171-9.

62. Paige JT, Kozmenko V, Yang T, Gururaja RP, Hilton CW, Cohn I Jr, et al. Attitudinal changes resulting from repetitive training of operating room personnel using of high-fidelity simulation at the point of care. Am Surg. 2009;75:584-90.

63. Weller J, Frengley R, Torrie J, Shulruf B, Jolly B, Hopley L, et al. Evaluation of an instrument to measure teamwork in multidisciplinary critical care teams. BMJ Qual Saf. 2011;20:216-22.

64. Cook D, Zendejas B, Hamstra S, Hatala R, Brydges R. What counts as validity evidence? Examples and prevalence in a systematic review of simulation-based assessment. Adv Health Sci Educ. 2013.

65. Arriaga A, Bader A, Wong J, Lipsitz S, Berry W, Ziewacz J, et al. Simulation-based trial of surgical-crisis checklists. NEJM. 2013;368:246-53. 